\title{
SIMULATION OF A BI-DIRECTIONAL DC-DC CONVERTER FOR PV APPLICATIONS
}

\author{
Dr.R.Seyezhai and M.UmaMaheswari
}

Associate Professor, Department of EEE, SSN College of Engineering, Chennai.

\begin{abstract}
Bi-directional DC-DC converter allows transfer of power between two dc sources, in either direction. In this paper the proposed converter is a combination of two topologies, namely half bridge on the primary and a current fed push pull on the secondary side of a high frequency isolation transformer. Thus providing the desired bi-directional flow of power for battery charging and discharging using only one transformer, as opposed to two in conventional schemes. In this paper, the operation of the converter in charging and discharging modes in open and closed loop is discussed and the simulations results are verified. The circuit configuration has been simulated using PSPICE. Comparisons of the simulation results for open loop and closed loop control system is performed. The results show that closed loop control system reduces distortion and the dynamic response of the converter is improved.
\end{abstract}

\section{KEYWORDS}

Bi-directional DC-DC converter, forward and reverse charging modes, PSPICE and closed loop

\section{INTRODUCTION}

Choppers are widely used to obtain a variable DC output voltage from a constant DC voltage. It can be used for step-up and step down operation. Implementation of bidirectional converters using resonant, soft switching and hard switching PWM are reported in the literature[1]. But, these topologies may often lead to an increase in component ratings, circuit complexity and conduction losses in resonant mode implementations, high output current ripple and loss of soft switching at light loads for soft-switched circuits, and lack of galvanic isolation in integrated topologies[2]. But this paper presents a bidirectional dc-dc converter topology for battery charger/discharger. In the proposed topology, the bi-directional power flow is achieved by two topologies namely half bridge and current fed push-pull topology. The primary side of the converter is a half bridge and is connected to the dc mains. The secondary side, connected to the battery, forms a current-fed push-pull. The benefits of a current fed push-pull converter are reduced switching losses in push-pull stage and the output rectification can be easily optimized. Simulation studies of the proposed converter is carried out using PSPICE. The proposed converter topology with feedback has been presented and simulated using PSPICE. The converter demonstrates high efficiency ( $86.6 \%$ in the forward mode and $90.5 \%$ in the backup mode), low part count due to its bi-directional feature and galvanic isolation. The results are verified.

\section{DESCRIPTION OF BI-DIRECTIONAL DC-DC CONVERTER}

Fig. 1 shows the power circuit of a bidirectional converter which consists of a half-bridge converter at the primary side of a isolation transformer. In the secondary side, a current-fed push-pull topology is employed. The circuit have a balanced winding NP and two catching diodes

DOI : 10.14810/ecij.2015.4204 
$\mathrm{D}_{1}$ and $\mathrm{D}_{2}$ on the primary side of half bridge. They maintain the centre point voltage at the junction of $\mathrm{C}_{1}$ and $\mathrm{C}_{2}$ to one half of the input voltage Vs and thus preventing the "RUN AWAY" condition of saturation of the transformer core. For low power applications, the half-bridge is preferred over the full-bridge topology[3-5]. The circuit operation consists of two modes: forward charging mode and reverse discharging mode.

In forward charging mode the energy from the dc mains charges the battery over a specified input voltage range while powering the downstream load converter. In this mode of operation only the switches $S_{1}$ and $S_{2}$ are gated and the body diodes of the switches $S_{3}$ and $S_{4}$ provide battery side rectification. In reverse discharging mode the switches $S_{3}$ and $S_{4}$ are gated and the body diode of the switches $S_{1}$ and $S_{2}$ provides rectification at the load side. On failure of the dc mains, reversal of power flow occurs. Now, the battery supplies the load power at the dc voltage. In this mode battery discharges the energy, and given to the load hence it is called as reverse discharging mode[6-7].

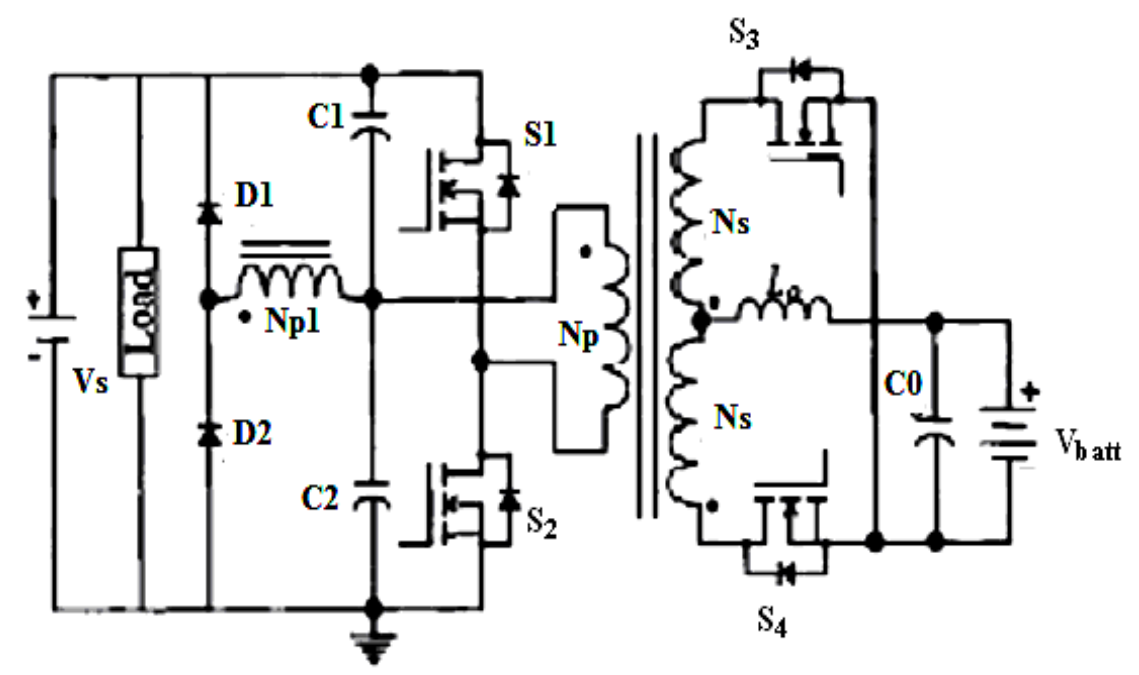

Fig.1.Power circuit of Bi-directional DC-DC Converter

\subsection{Forward Charging Mode}

In the forward charging mode as shown in Fig.2, main power supply Vs, powering the load converters, provides the battery charging current. This charges the battery of the bi-directional converter at the nominal voltage. The switches $S_{1}$ and $S_{2}$ on the primary side are gated at duty ratios less than 0.5, while $S_{3}$ and $S_{4}$ are not switched at all. Operation of the bi-directional converter during this mode is comparable to that of a buck converter. The various stages of operation during one switching time period, $T s$, are divided into four intervals $t_{0}-t_{4}[8]$. The converter operation is repetitive in the switching cycle. 

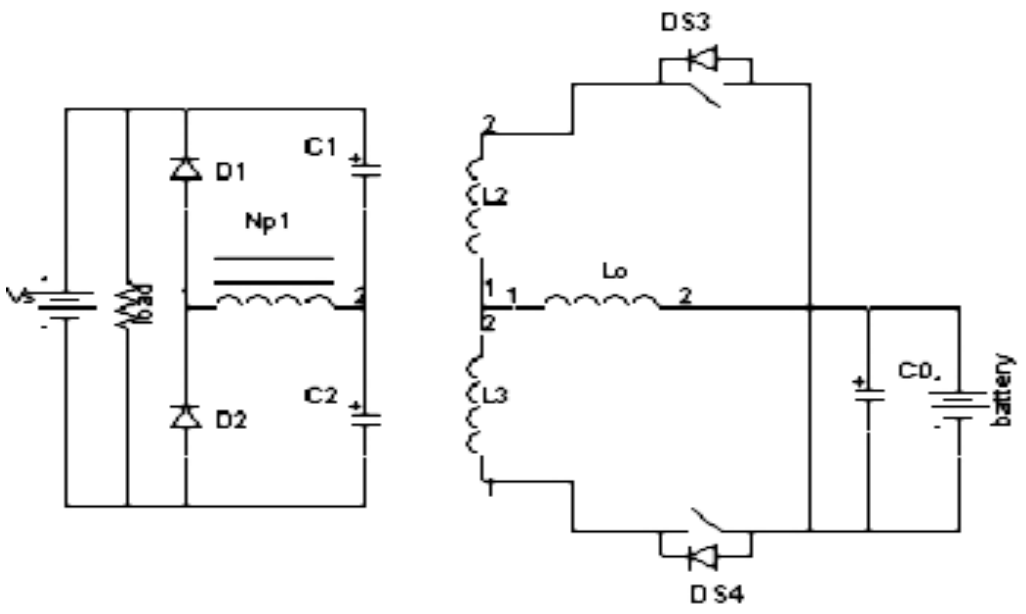

Fig.2.Forward Charging Mode

In the interval, to-t1, the switch $S_{1}$ is turned on by applying the gate pulse at t0 and the switch $S_{2}$ is in the off position. Because of the balancing winding and two catching diodes $\mathrm{D}_{1}$ and $\mathrm{D}_{2}$, the voltage that appears on the primary side of the transformer is $\mathrm{Vs} / 2$.In the secondary side the diode $\mathrm{DS}_{4}$ of switch $\mathrm{S}_{4}$ is forward biased and provides rectification. In this mode the inductor current increases linearly. The primary current, is ${ }_{1}$, builds up linearly with increasing inductor current $i_{10}$. In the interval $t_{1}-t_{2}$, the switch $S_{1}$ turned off at $t_{1}$ and switch $S_{2}$ remains in the off state. In this dead time interval there is no voltage across the primary, and there is zero voltage across the secondary winding and thus there is no power transferred to the secondary side. The stored inductor energy results in the freewheeling of current through the diode $\mathrm{DS}_{3}$ and $\mathrm{DS}_{4}$ to charge the battery. Only half of the supply voltage Vs, appears across the switch $S_{1}$ and $S_{2}$ during this interval.

During the interval $t_{2}-t_{3}, S_{2}$ is turned on and $S_{1}$ remains in the off state. During this interval voltage appears across the primary winding is $\mathrm{Vs} / 2$. In the secondary side the diode $\mathrm{DS}_{3}$ of switch $\mathrm{S}_{3}$ is forward biased and provides rectification. In this mode the inductor current increases linearly. The primary current, is $\mathrm{s}_{2}$ builds up linearly with increasing inductor current $\mathrm{iL}_{0}$. The battery charging current is carried by the body diode $\mathrm{DS}_{3}$. During $t_{3}-t_{4}$, the switch $S_{2}$ turned off at $t_{3}$ and switch $S_{1}$ remains in the off state. In this dead time interval there is no voltage across the primary, and there is zero voltage across the secondary winding and thus there is no power transferred to the secondary side. The stored inductor energy results in the freewheeling of current through the diode $\mathrm{DS}_{3}$ and $\mathrm{DS}_{4}$ to charge the battery. Only half of the supply voltage Vs appears across the switch $S_{1}$ and $S_{2}$ during this interval.

\subsection{Reverse Charging Mode}

In this mode the dc supply is not present then the load takes the power from the battery. As shown in Fig.3, the switches $S_{3}$ and $S_{4}$ are on the secondary side. But the switches $S_{1}$ and $S_{2}$ are not gated. The various stages of operation during one switching time period can be divided in to intervals are from $t_{0}-t_{4}$. 


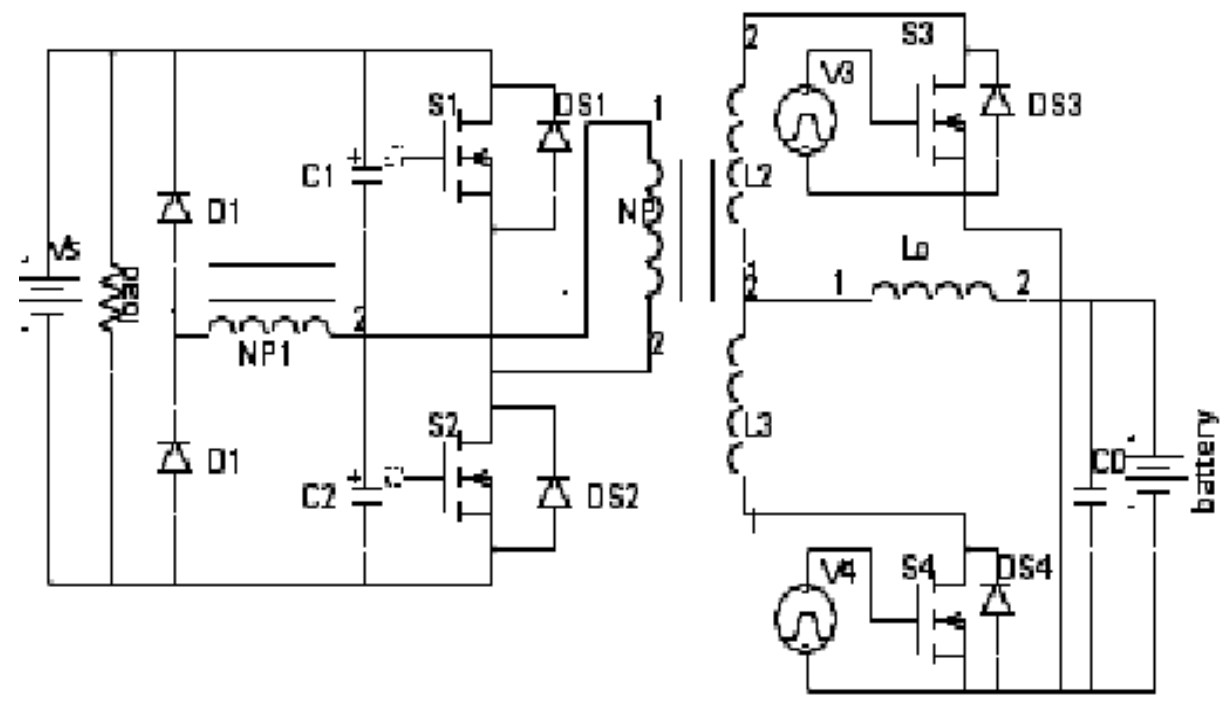

Fig.3.Reverse Discharging Mode

In the interval, $t_{0}-t_{1}$, the switch $S_{3}$ is turned on by applying the gate pulse at $t_{0}$ and the switch $S_{4}$ remains in the on state. The transformer secondary, Ns, is subject to an effective short circuit, which causes the inductor, Lo, to store energy as the total battery voltage appears across it. The inductor current, $i_{\text {Lo }}$, increase linearly and shared equally by both the switches $S_{3}$ and $S_{4}$.During $t_{1}-t_{2}$, the switch $S_{4}$ is turned off at $t_{1}$ while $S_{3}$ remains in the on state. The energy stored in the inductor, Lo, during the previous interval is now transferred to the load through the body diode $\mathrm{DS}_{2}$ and the diode $\mathrm{D}_{1}$. Voltage across the auxiliary winding $\mathrm{NP}_{1}$ and the primary winding $\mathrm{Np}$ is identical due to the equal number of turns. This allows simultaneous and equal charging of both $\mathrm{C}_{1}$ and $\mathrm{C}_{2}$ through $\mathrm{D}_{1}$ and $\mathrm{DS}_{2}$, respectively.

In $t_{2}-t_{3}$, the switch $S_{4}$ is turned on by applying the gate pulse at $t_{0}$ and the switch $S_{3}$ remains in the on state. The transformer secondary, Ns, is subject to an effective short circuit, which causes the inductor, Lo, to store energy as the total battery voltage appears across it. The inductor current, $\mathrm{iL}_{\mathrm{o}}$, increase linearly and shared equally by both the switches $S_{3}$ and $S_{4}$. During the interval, $t_{3}-t_{4}$, the switch $S_{3}$ is turned off at $t_{1}$ while $S_{4}$ remains in the on state. The energy stored in the inductor, Lo, during the previous interval is now transferred to the load through the body diode $\mathrm{DS}_{1}$ and the diode $\mathrm{D}_{2}$. Voltage across the auxiliary winding $\mathrm{NP}_{1}$ and the primary winding $\mathrm{Np}$ is identical due to the equal number of turns. This allows simultaneous and equal charging of both $C_{1}$ and $C_{2}$ through $\mathrm{D}_{2}$ and $\mathrm{DS}_{1}$.

\section{DESIGN EQUATIONS AND SIMULATION RESULTS}

The proposed bidirectional DC-DC converter is designed as follows [9]:

The duty ratio is calculated as

$$
d_{\max }=\frac{V_{\text {battery } \max }}{V_{S \min }}
$$


Electrical \& Computer Engineering: An International Journal (ECIJ) Volume 4, Number 2, June 2015

$$
d_{\min }=\frac{V_{\text {battery } \max }}{V_{S \max }}
$$

The minimum value of inductance is calculated as follows:

$$
L_{\text {min }}=\frac{V_{\text {battery } \max }\left(1-2 d_{\min }\right)}{4 f_{s} I_{\min }}
$$

The output capacitor is calculated as follows:

$$
C_{O}=\frac{L_{O} I_{\text {battery } \max }^{2}}{V_{\text {batterypeak }}^{2}-V_{\text {batteryripple }}^{2}}
$$

The value of input capacitors are determined as

$$
C_{1}=C_{2}=\frac{2 I_{\text {primary }} t_{\text {disch } \arg e}}{V_{\text {ripple }}}
$$

Using the above design equations, the simulation parameters are shown in Table:1

Table:1 Simulation parameters of Bidirectional DC-DC converter

\begin{tabular}{|l|l|}
\hline \multicolumn{1}{|c|}{ Parameters } & \multicolumn{1}{c|}{ Values } \\
\hline Input voltage & $380 \mathrm{~V}$ \\
\hline Operating frequency & $100 \mathrm{kHz}$ \\
\hline Nominal battery voltage & $48 \mathrm{~V}$ \\
\hline Output power & $85 \mathrm{~W}$ \\
\hline Duty ratio & 0.5 \\
\hline Inductance & $360 \mathrm{uH}$ \\
\hline Output Capacitor $\mathrm{C}_{\mathrm{o}}$ & $470 \mathrm{uF}$ \\
\hline Input Capacitor $\mathrm{C}_{1} \& \mathrm{C}_{2}$ & $150 \mathrm{uF}$ \\
\hline
\end{tabular}

Fig.4 shows the voltage across $S_{1}$ and $S_{2}$ and the voltage is about $380 \mathrm{~V}$ in the forward charging mode. 
Electrical \& Computer Engineering: An International Journal (ECIJ) Volume 4, Number 2, June 2015

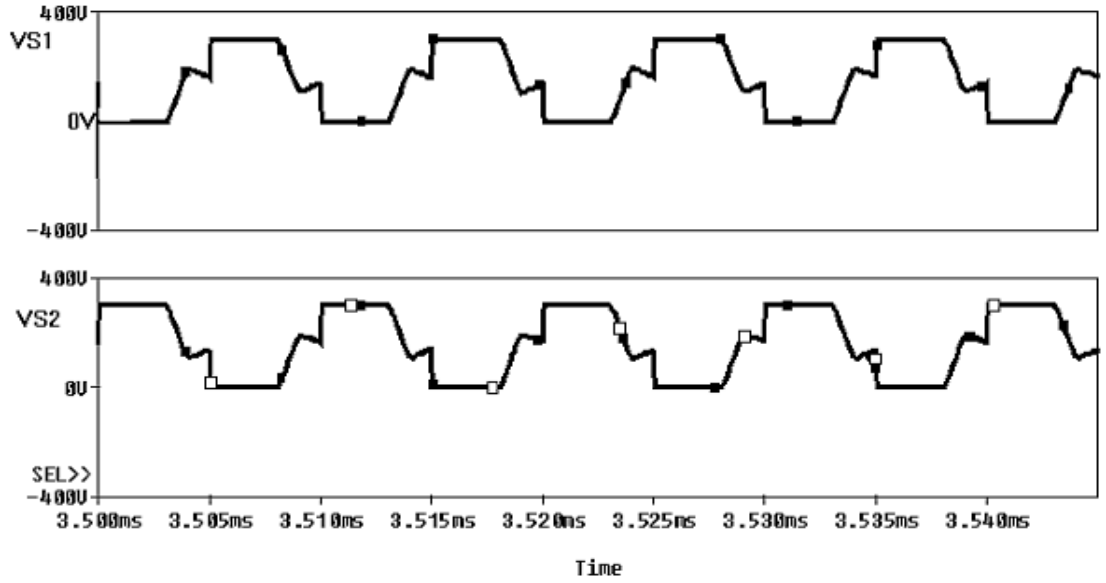

Fig.4.VoltageWaveform across Switch $\mathrm{S}_{1}$ and $\mathrm{S}_{2}$

Fig.5 shows the voltage and current through the inductor
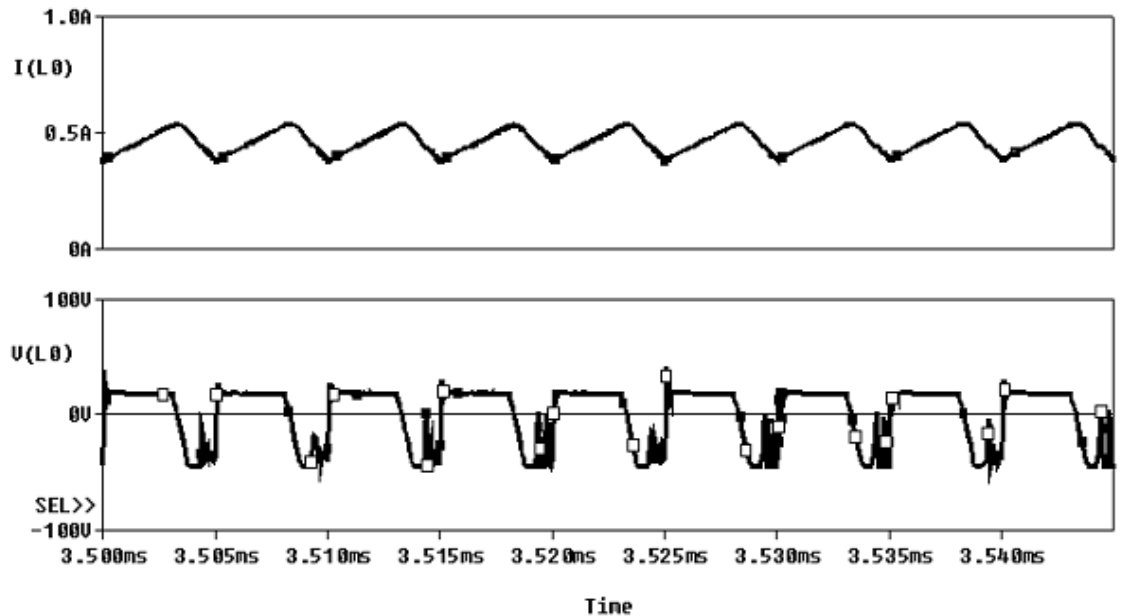

Fig.5.Current through $\mathrm{L}_{0}$ and voltage across $\mathrm{L}_{0}$. 
Electrical \& Computer Engineering: An International Journal (ECIJ) Volume 4, Number 2, June 2015
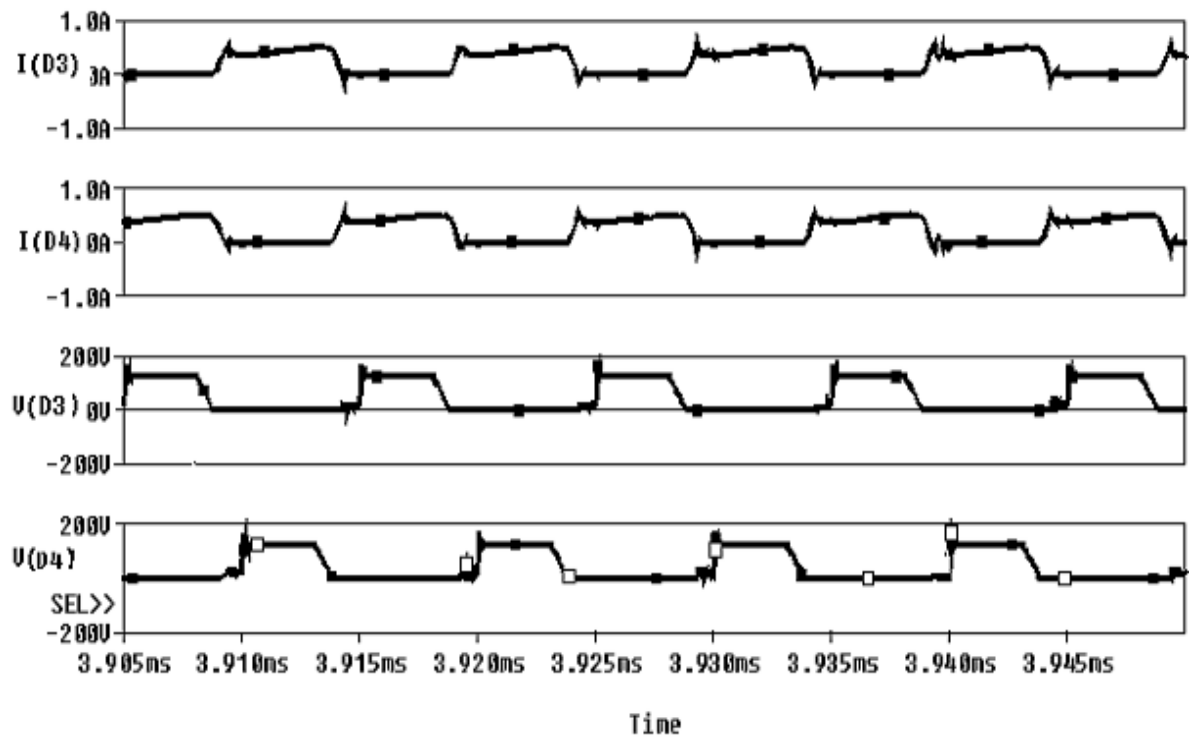

Fig.6.Current through $\mathrm{D}_{\mathrm{S} 3}, \mathrm{D}_{\mathrm{S} 4}$ and Voltage across Switch $\mathrm{S}_{3}, \mathrm{~S} 4$

In the reverse discharging mode, the voltage across $S_{3}$ and $S_{4}$ is shown in Fig.7.

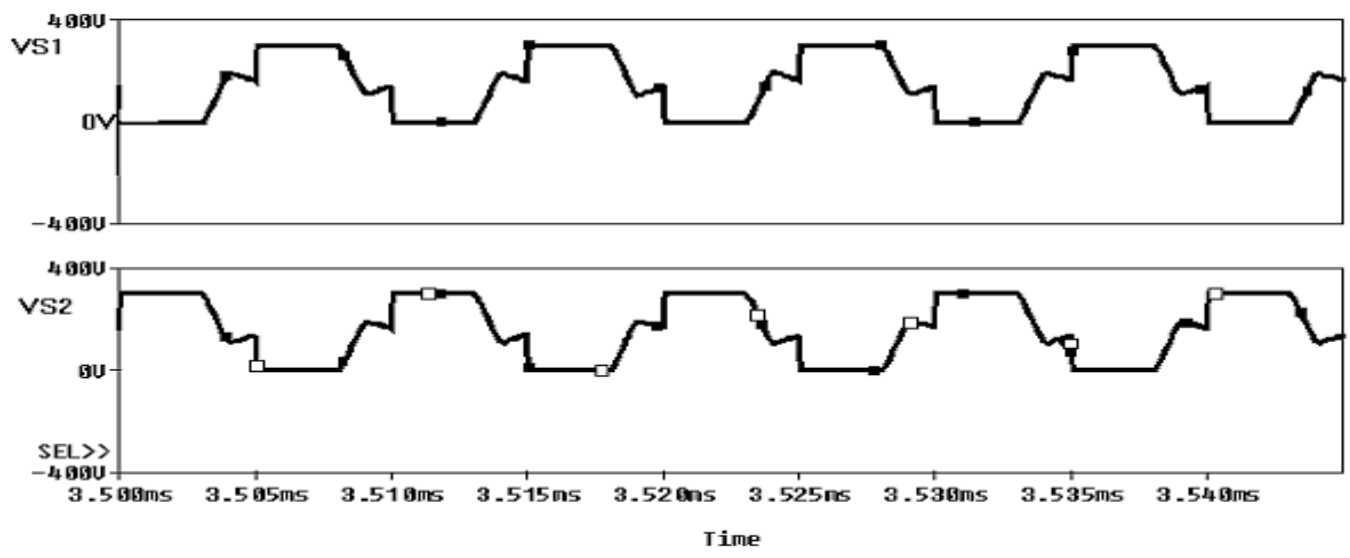

Fig.7.Voltage across switch $\mathrm{S}_{3}$ and $\mathrm{S}_{4}$ 
Electrical \& Computer Engineering: An International Journal (ECIJ) Volume 4, Number 2, June 2015

Fig. 8 shows the voltage and current through the inductor
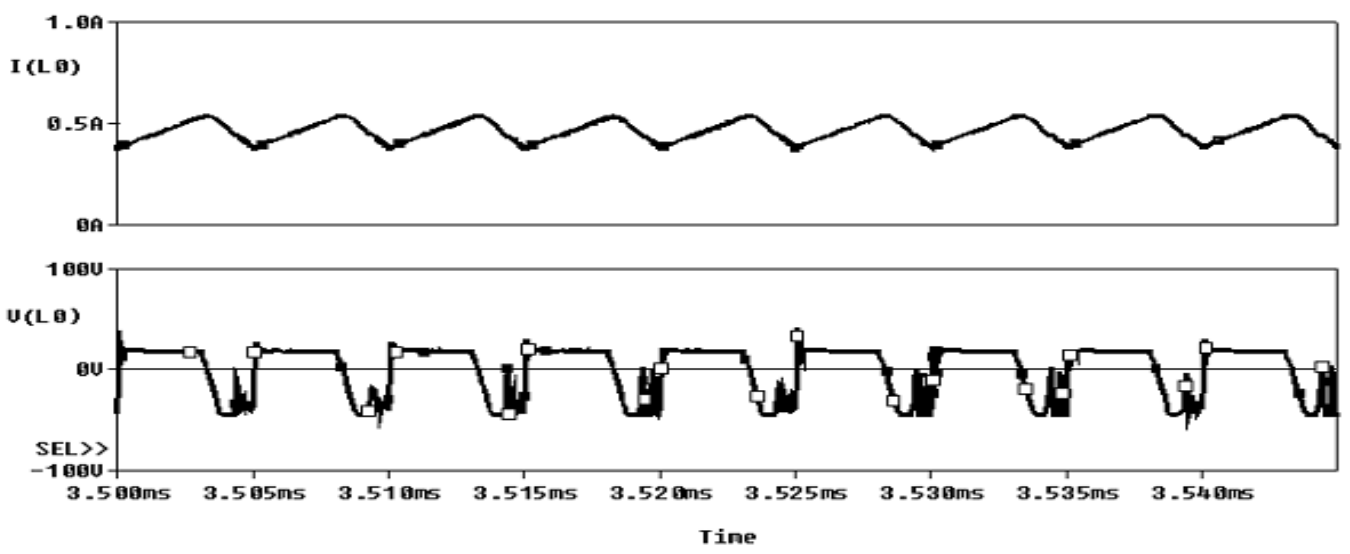

Fig.8. Current through $\mathrm{L}_{0}$ and voltage across $\mathrm{L}_{0}$

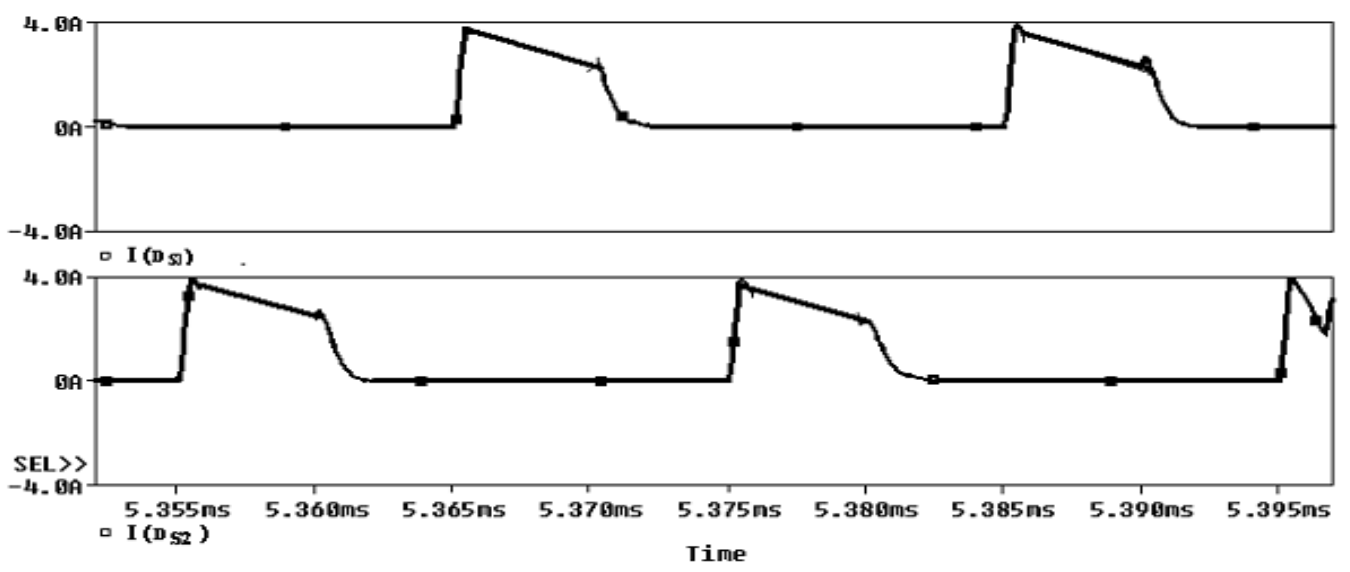

Fig.9.Current through $\mathrm{DS}_{1}$ and $\mathrm{DS}_{2}$

Figs. 9 \& 10 show the current through $\mathrm{DS}_{1}$ and $\mathrm{DS}_{2}$ and voltage across $\mathrm{S}_{1} \& \mathrm{~S}_{2}$.
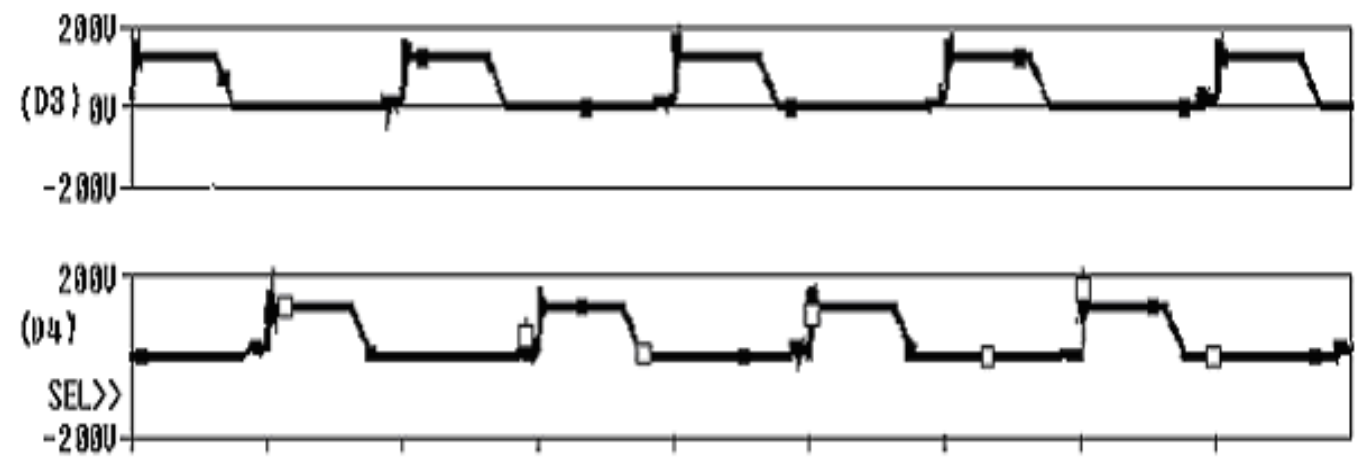

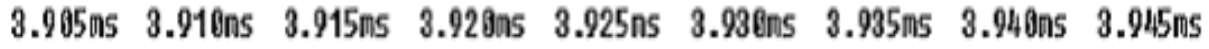

\section{Tine}

Fig.10.Voltage across switch $\mathrm{S}_{1}$ and $\mathrm{S}_{2}$ 
Electrical \& Computer Engineering: An International Journal (ECIJ) Volume 4, Number 2, June 2015

In order to improve the dynamic response of the converter, a closed loop control is implemented[10]. A compensated error amplifier is added in the feedback path. This amplifier reduces the steady-state error and the compensation circuit is shown in Fig.11.

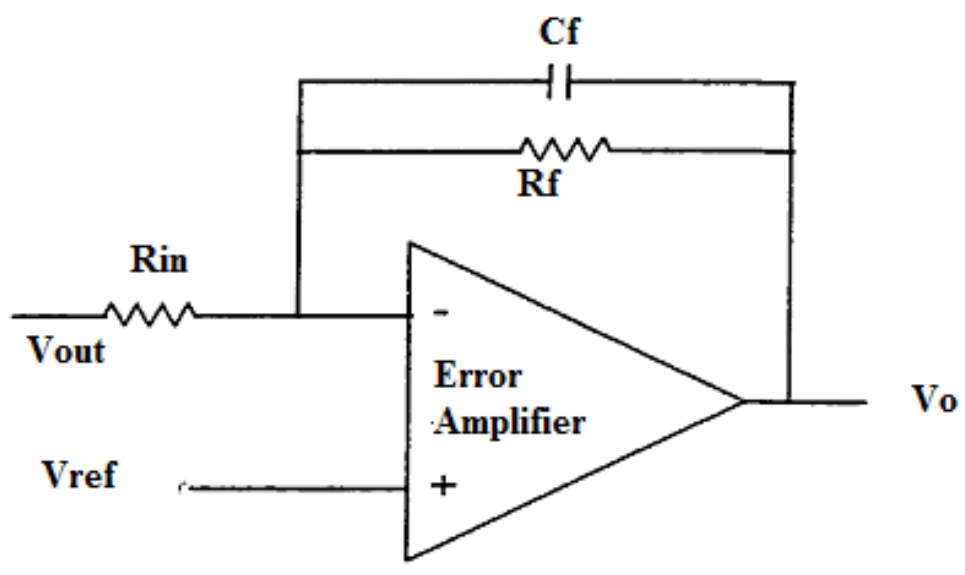

Fig.11 Compensation circuit for the error amplifier

The values of the feedback elements are properly chosen so that the dynamic response of the converter is faster. Fig. 12 shows the voltage across the load without disturbance in open loop condition under forward charging mode.

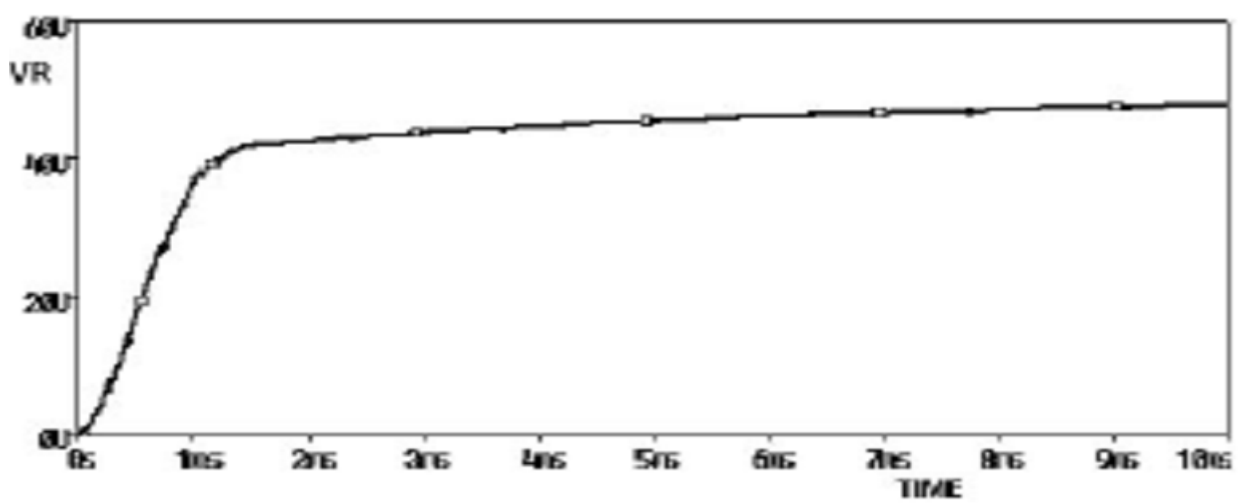

Fig.12 Voltage across load without disturbance in open loop condition

At $\mathrm{t}=4 \mathrm{~ms}$, a disturbance is provided and the voltage across the load is shown in Fig.13.Fig.14 shows the output voltage of op-amp. 
Electrical \& Computer Engineering: An International Journal (ECIJ) Volume 4, Number 2, June 2015

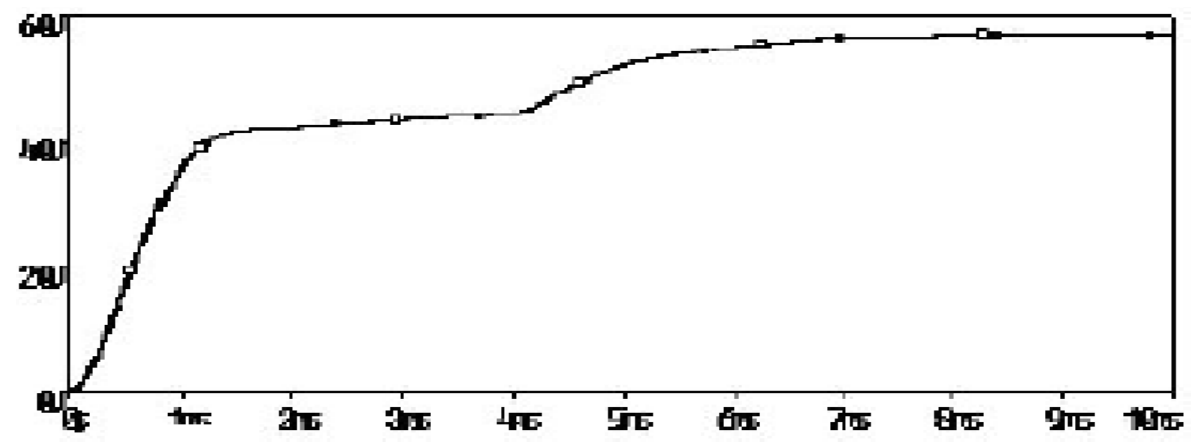

Fig.13.Voltage across the load with disturbance provided at $4 \mathrm{~ms}$

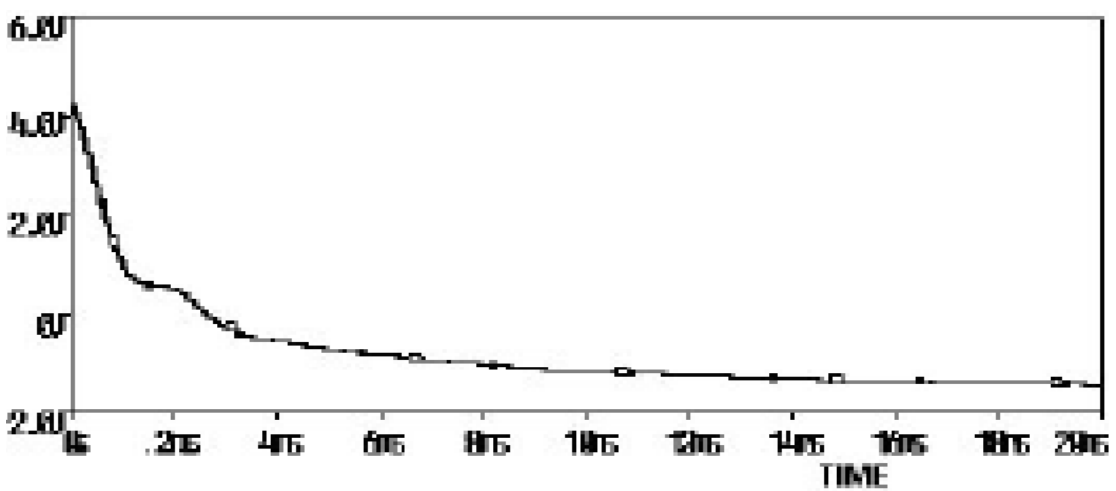

Fig.14.Output voltage of Op-amp

In the reverse charging mode, the voltage across the load in open loop condition is shown in Fig.15.

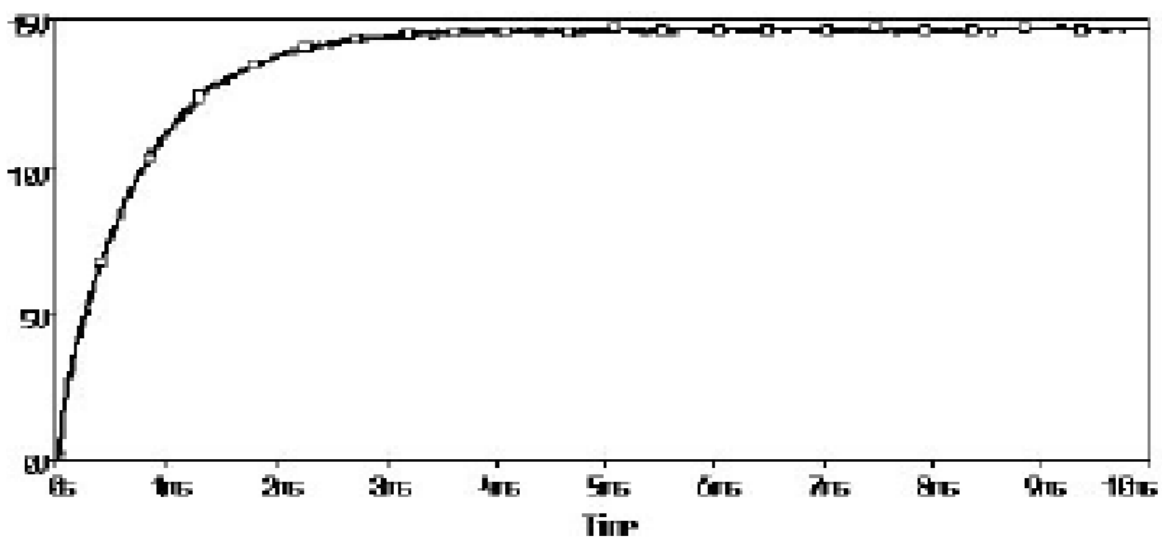

Fig.15.Voltage across load without disturbance in open loop condition

At $\mathrm{t}=4 \mathrm{~ms}$, a disturbance is provided and the voltage across the load is shown in Fig.16.Figs.17 \& 18 shows the output voltage of op-amp and proportional controller. 
Electrical \& Computer Engineering: An International Journal (ECIJ) Volume 4, Number 2, June 2015

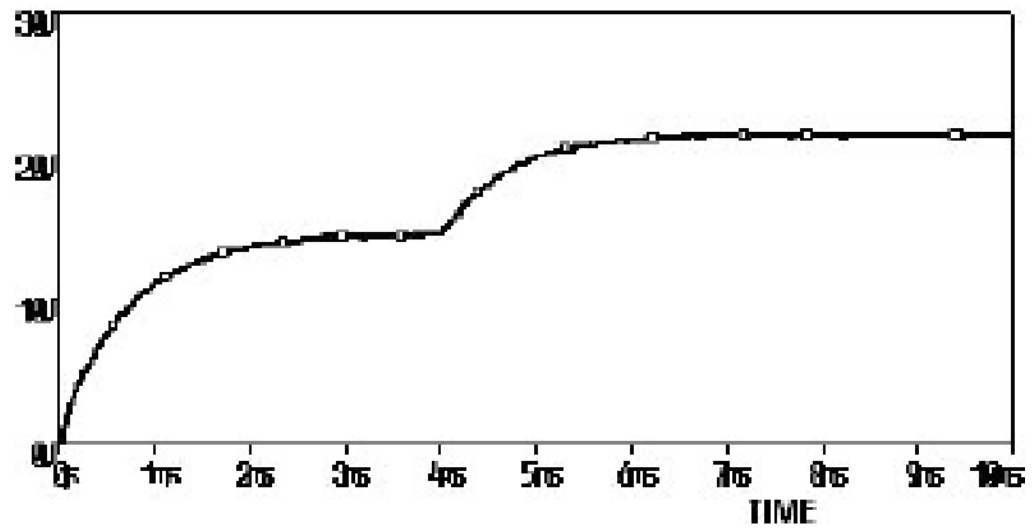

Fig.16.Voltage Across Load With Disturbance TD=4ms

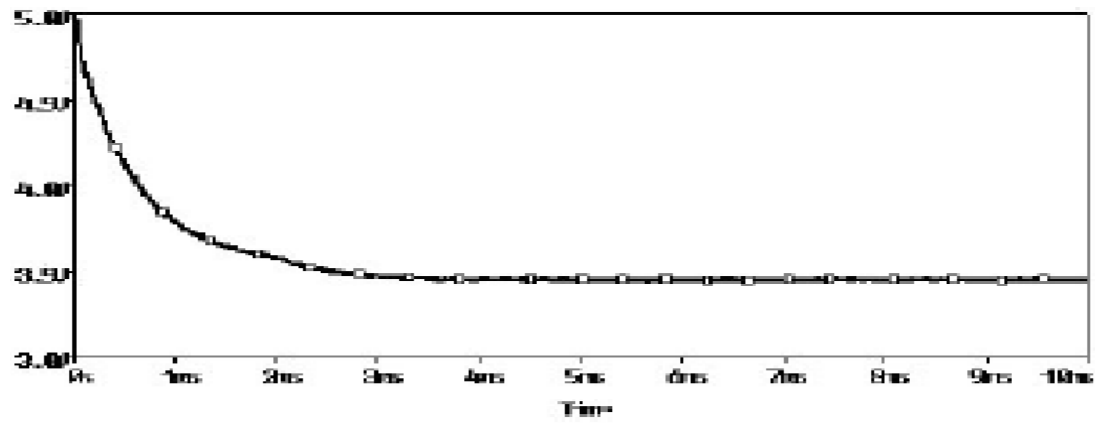

Fig.17.OPAMP output voltage

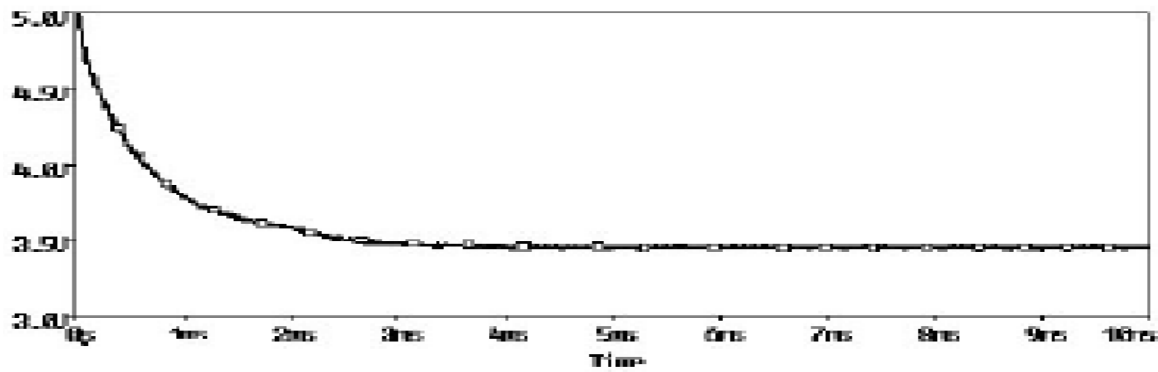

Fig.18. Output voltage across proportional voltage controller

With closed loop control, the output voltage of the bidirectional converter is controlled both in the forward and reverse charging modes.

\section{CONCLUSION}

A bi-directional DC-DC converter in forward and reverse charging modes have been presented in this paper. Moreover, to improve the dynamic response of the converter, a feedback system is also employed and the output voltage is regulated. Therefore, the proposed converter will be a suitable topology for PV applications. 
Electrical \& Computer Engineering: An International Journal (ECIJ) Volume 4, Number 2, June 2015

\section{REFERENCES}

[1] H. G. Langer and H. -Ch. Skudelny (1989), "DC to DC converters with bi-directional power flow and controllable voltage ratio," in Proc. IEE EPE Conf., pp. 1245-1250.

[2] Capel (1986), "A bidirectional high power cell using large signal feedback control with maximum current control for space applications," in Proc. IEEE Power Electron. Spec. Conf., pp. 684-695.

[3] K. Venkatesan (1989), "Current mode controlled bidirectional fly back converter," in Proc. IEEE Power Electron. Spec. Conf, pp. 835-842.

[4] Ray (1992), "Bidirectional dc-dc power conversion using quasiresonant topology," in Proc. IEEE Power Electron. Spec. Conf., pp. 617-624.

[5] Inoue, S. \& Akagi, H. (2007). A Bidirectional DC-DC converter for an Energy storage system With Galvanic Isolation. IEEE Transactions on Power Electronics, Vol. 22, No. 6, (2007), pp. 2299-2306, ISSN 0885-8993.

[6] Krismer, F., Biela J. \& Kolar, J.W. (2005). A comparative evaluation of isolated bi-directional DC/DC converters with wide input and output voltage range, Proceedings of the Fourtieth IAS Annual Meeting, Vol.1, pp. 599-606.

[7] Yu, W., Qian, H. and Lai, J.S. (2010), "Design of High-Efficiency Bidirectional DC-DC Converter and High-Precision Efficiency Measurement", IEEE Transactions on Power Electronics, Vol. 25, No. 3, pp. 650-658.

[8] Tao, T., Duarte, J.L. \& Hendrix, M.A.M. (2008). Three-Port Triple-Half-Bridge Bidirectional Converter With Zero-Voltage Switching. IEEE Transactions on Power Electronics, Vol. 23, No. 2, pp. 782-792.

[9] Yu, W., Qian, H. \& Lai, J.S. (2010). Design of High-Efficiency Bidirectional DC-DC Converter and High-Precision Efficiency Measurement. IEEE Transactions on Power Electronics, Vol. 25, No. 3, (March 2010), pp. 650-658, ISSN 0885-8993.

[10] Sheng-Yuan Ou , Ho-Pu Hsiao and ChenHung Tien (2010), "Analysis and Design of a Prototype Single-Stage Half-Bridge Power Converter,’2010 5th IEEE Conference on Industrial Electronics and Applications, pp.1168-1173. 